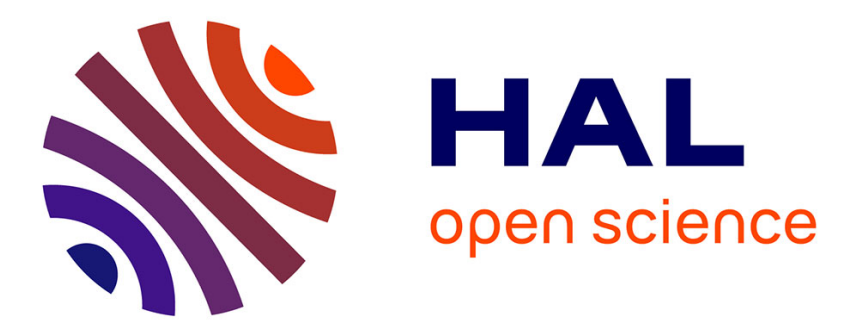

\title{
On listening to atonal variants of two Piano Sonatas by Beethoven
}

Philippe Lalitte, Emmanuel Bigand, Joanna Kantor-Martynuska, Charles Delbé

\section{To cite this version:}

Philippe Lalitte, Emmanuel Bigand, Joanna Kantor-Martynuska, Charles Delbé. On listening to atonal variants of two Piano Sonatas by Beethoven. Music Perception, 2009, 26 (3), pp.223-234. halshs-00564525

\section{HAL Id: halshs-00564525 \\ https://shs.hal.science/halshs-00564525}

Submitted on 11 Apr 2017

HAL is a multi-disciplinary open access archive for the deposit and dissemination of scientific research documents, whether they are published or not. The documents may come from teaching and research institutions in France or abroad, or from public or private research centers.
L'archive ouverte pluridisciplinaire HAL, est destinée au dépôt et à la diffusion de documents scientifiques de niveau recherche, publiés ou non, émanant des établissements d'enseignement et de recherche français ou étrangers, des laboratoires publics ou privés. 
On Listening to Atonal Variants of Two Piano Sonatas by Beethoven Author(s): Philippe Lalitte, Emmanuel Bigand, Joanna Kantor-Martynuska and Charles Delbé

Source: Music Perception: An Interdisciplinary Journal, Vol. 26, No. 3 (February 2009), pp. 223-234

Published by: University of California Press

Stable URL: http://www.jstor.org/stable/10.1525/mp.2009.26.3.223

Accessed: 10-04-2017 09:30 UTC

JSTOR is a not-for-profit service that helps scholars, researchers, and students discover, use, and build upon a wide range of content in a trusted digital archive. We use information technology and tools to increase productivity and facilitate new forms of scholarship. For more information about JSTOR, please contact support@jstor.org.

Your use of the JSTOR archive indicates your acceptance of the Terms \& Conditions of Use, available at http://about.jstor.org/terms

University of California Press is collaborating with JSTOR to digitize, preserve and extend access to Music Perception: An Interdisciplinary Journal 


\section{On Listening to Atonal Variants of two Piano Sonatas BY BeETHOVEN}

\author{
Philippe Lalitte and Emmanuel Bigand \\ LEAD-CNRS, Université de Bourgogne, Dijon, France \\ JOANNA KANTOR-MARTYNUSKA \\ Warsaw School of Social Sciences and Humanities, \\ Warsaw, Poland \\ Charles Delbé \\ LEAD-CNRS, Université de Bourgogne, Dijon, France
}

WE INVESTIGATED THE CONTRIBUTION OF TONAL relationships to the perception of musical ideas and to the feelings of "arousal." Two excerpts of piano sonatas by Beethoven and two atonal variants were used as experimental stimuli. This manipulation destroyed the tonal relationships but preserved both the local and global temporal organization (rhythm and formal). Listeners were asked to indicate the onset of musical ideas, to estimate the arousing properties of the music in a continuous response task, and to rate the similarity of the pieces. A drastic change in the pitch structure strongly affected judgments of similarity. However, it had no effect on the segmentation of musical ideas, nor on the response of arousal. This finding emphasizes the importance of local and global levels of temporal structures on perceptual and emotional judgments, at the cost of the influence of tonal relationships.

Received June 6, 2008, accepted September 29, 2008.

Key words: arousal, form, similarity, temporal organization, tonal relationships

$\mathrm{L}$ ARGE-SCALE STRUCTURES IN WESTERN MUSIC are organized by three musical dimensions: temporal $\mathcal{U}$ (meter, rhythm, and tempo), thematic (motif and phrase), and harmonic (tonal relationships and prolongations). The musical dimensions that most significantly contribute to large-scale structure have not yet been determined and are still a subject of debate both in musicology and music cognition. The most common assumption is that musical form is constrained by tonal hierarchies; however, there is no evidence as to which dimension - pitch structure or temporal structure-has a decisive role in perception of musical form. This issue became significant at the beginning of the 20th century with the abandonment of tonal hierarchies by the Second Viennese School: Schoenberg, Berg, Webern, and others. The apparent absence of harmonic functions might tend to cause problems in building large-scale structures. The shortness of the first atonal pieces (for instance Six Little Piano Pieces, Op. 19 by Schoenberg or Six Bagatelles for String Quartet, Op. 9 by Webern) suggested that tonal hierarchies were of considerable importance in structuring musical time. The present study investigated this issue by drastically manipulating the pitch structure of musical excerpts three minutes in duration.

\section{Music Theory Perspective}

Since the mid-eighteenth century, music theorists have worked out two opposing models of musical form that are often called architectonism and organicism. In architectonism (Cooper \& Meyer, 1960; Czerny, 1979; Kirnberger, 1757; Koch, 1983; Riemann, 1882) musical form is considered as a combination of patterns, motifs, sentences, and periods organized according to the principles of symmetry and repetition. Representing an architectonic perspective, Riemann's Phraseological Theory (1882), in referring to melodic, rhythmic, and harmonic motifs, claimed that "Motif in music, as in architecture, is the most basic characteristic part of an artistic structure" (p. 605). On the other hand, organicism (Marx, 1847; Momigny, 1806; Salzer, 1952; Schenker, 1935/1979; Schering, 1911) considers musical form as a living organism in which the structure unfolds from a seed. Schenker's Theory of Organic Coherence (1935/1979) regarded musical form as deployment of a fundamental structure (Ursatz) by means of techniques of prolongation leading to the construction of numerous musical forms. According to Zbikowski (2002), the architectonist model (which he calls atomistic hierarchies) "does a good job of capturing the regularity and nesting of accentual patterns typical of musical meter" (p. 310), whereas the organicist

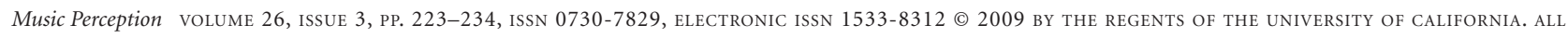
RIGHTS RESERVED. PLEASE DIRECT ALL REQUESTS FOR PERMISSION TO PHOTOCOPY OR REPRODUCE ARTICLE CONTENT THROUGH THE UNIVERSITY OF CALIFORNIA PRESS'S RIGHTS AND PERMISSIONS WEBSITE, HTTP://WWW.UCPRESSJOURNALS.COM/REPRINTINFO.ASP. DOI:10.1525/MP.2009.26.3.223 
model (which he calls chain-of-being hierarchies) "does a good job of capturing the harmonic and scale-degree dependencies" (p. 310). In analyzing tonal music, organicist authors have a tendency to focus on the nonthematic level (perceptual background), while architectonist authors are preoccupied by the thematic level (foreground) of a musical composition.

Compared to these extreme models, contemporary theoretical works represent a more balanced approach. In the Generative Theory of Tonal Music (GTTM), Lerdahl and Jackendoff (1983) describe musical structures in terms of hierarchies involving four main dimensions (grouping structure, metric structure, time-span reduction, and prolongational reduction). Pitch stability conditions (i.e., tonal hierarchies) play a crucial role in deriving the underlying structures of Western musical pieces. According to GTTM, tonal hierarchies combine with rhythmic structures (grouping and meter) to define the event hierarchies of long musical pieces. Thematic relationships are nonhierarchic structures but they indirectly contribute to the overall form of an event hierarchy through their influence on the grouping and metrical structures. Event hierarchies may be derived by GTTM from atonal pieces. In this case, prolongational analyses are feasible, in a similar way to those in tonal music, via time-span segmentation and prolongational reduction. The principal difference between tonal and atonal prolongation derivations lies in the relative role of stability and salience. The stability conditions play a weak role in atonal music, whereas salience features tend to replace the tonal hierarchies. According to Lerdahl (2001), "Because of this redistribution in weightings ... and because salience affords fewer and less regular hierarchical distinctions than does stability, atonal prolongation structures tend to be perceptually fragile and of limited hierarchical depth" (p. 348).

\section{Cognitive Psychology Perspective}

Practical experiments seem to yield puzzling data: most experiments report the considerable difficulty experienced by listeners in following large scale organization in music, whether these organizations deal with Western pitch hierarchies or thematic relationships. For example, Cook (1987) reported that tonal closure was perceived only for very short pieces (less than 1 minute). Similar results were obtained when explicit judgments were made about whether an excerpt ended in the same or a different tonality than the initial one (Marvin \& Brinkman, 1999). Using a musical jigsaw task, Tillmann, Bigand, and Madurell (1998) found that both musicians and nonmusicians understood the local functions of cadences but were unable to integrate these local structures into the overall global structure of a musical piece. In the same way, the perception of thematic relationships in rather long musical pieces (Francès, 1958) was found to be extremely difficult, even for listeners with music training, and even when participants were informed about the structure of the piece before listening.

More surprising findings have been in numerous other studies. Changing the whole organization of musical pieces consistently was found to have a weak (if any) effect on listeners (Gotlieb \& Konecni, 1985; Karno \& Konecni, 1992; Tillmann \& Bigand, 1996). This set of data is all the more puzzling in that other studies carried out with atonal musical pieces revealed some ability to perceive the overall organization of a musical atonal piece (Deliège; 1989; Clarke \& Krumhansl, 1990). Lalitte et al. (2004) investigated the perceptual structure of the five themes of The Angel of Death by Roger Reynolds. In the first phase, participants performed segmentation of the musical ideas while listening to the piece. In the second phase, they were presented pairs of extracts of themes, and their task was to judge whether the extracts belonged to the same theme. Segmentation responses were strongly influenced by the rhetorical structure of the themes. However, listeners encountered difficulties when they were asked to perform more abstract tasks such as judgment of belongingness. In a study carried out at the premier concerts of The Angel of Death (McAdams, Vines, Vieillard, Smith, \& Reynolds, 2004), listeners continuously rated one of two dimensions: familiarity (resemblance of musical material within the piece) or emotional force. The study revealed the influence of large-scale musical form and context on recognition processes and listener's emotional reactions.

The data reported in this review question the contribution of tonal hierarchies to large-scale structures. On the one hand, several studies of tonal music emphasize the difficulty of perceiving large-scale structure in tonal music. On the other hand, studies of atonal music provide evidence that tonal hierarchies are not indispensable for the perception of large musical organization (such as rhetorical organization). In the best case, consistent but moderate sensitivity to large-scale structures were reported for both tonal popular music (rock, jazz) and atonal music (Lalitte \& Bigand, 2006).

The main purpose of the present study was to further investigate this issue by directly assessing the influence of tonal hierarchies on the perception of musical pieces three minutes in duration. The critical new point was 
the manipulation of the pitch content of the pieces. The pitch content of two of Beethoven's sonatas (Sonata No. 21 in C major, Op. 53 and Sonata No. 17 in D minor, Op. 31/2, labeled Waldstein and Tempest, respectively) were drastically altered while keeping constant the rhythm, the tempo, the dynamic, and the temporal organization of musical ideas (see below for details). This manipulation resulted in two atonal pieces (labeled Stadwilen and Estempt, respectively) that shared with their tonal counterparts the same metric and grouping structures, but differed in the pitch stability conditions. If tonal hierarchies strongly contribute to Western listeners' understanding of large-scale structure, these changes should strongly affect the apparent segmentation of the musical ideas, and the continuous response to the arousal value of the pieces. These effects should be more pronounced in listeners highly trained in tonal music. In other words, if contemporary composers were to rework the pitch structure of Western tonal masterpieces, would this result in entirely new musical pieces or would the listeners continue to perceive some invariant features?

\section{Method}

\section{Participants}

Fifty-two participants volunteered for the experiment. Thirty-six were students of an introductory psychology course at the Université de Bourgogne. A preliminary questionnaire indicated that none had formal training in music, and could thus be considered "nonmusicians." Sixteen candidates for the final diploma in music education in the Dijon Music Conservatory were regarded as "musicians". The musicians were familiar with contemporary music, notably because performance and analysis of contemporary pieces formed part of the conservatory curriculum.

\section{Stimuli and Apparatus}

We manipulated the pitch content of two of Beethoven's piano sonatas (Sonata No. 21 in C major, Op. 53 and Sonata No. 17 in D minor, Op. 31/2, labeled Waldstein and Tempest, respectively. In order to obtain two atonal counterparts of tonal excerpts (respectively labeled Stadwilen and Estempt), the pitch content (pitch, intervals, pitch contour, register, pitch density) was entirely reorganized with a pseudorandom process with constraints. The variant pieces were composed in a free but coherent atonal style (neither the twelve-tone technique, nor a random algorithm were used) in such a way as to give an equal distribution of the pitch-classes (Figure 1) Full and half cadences were not included, and major, minor, and dominant seventh chords were avoided in order to remove tonal relationships. Thus, in contrast to the original pieces, the distribution was almost flat in the atonal pieces. The change in pitch structure was performed without modifying the thematic organization of the pieces. That is to say, when a motif recurred in the original piece, the atonal version of this motif was repeated at the same place in the counterpart. In order to conform to this principle, we kept the formal functions (see Caplin, 1998) as congruent as possible between originals and counterparts. Presentational, developmental, transitional, and closure sections were maintained in the same position as in the original piece.

Recordings of Beethoven's Waldstein sonata performed by Wilhelm Kempff, and of the Tempest sonata performed by Inger Södergren, were used as the experimental material. The performances were selected so that the two sonata expositions were balanced in duration. The beginning of the reprise was included in the musical material to form two excerpts of $148 \mathrm{~s}$ each. The altered versions of the Waldstein and Tempest sonatas were composed and recorded in MIDI format with Steinberg Cubase SX 2 Software and The Grand VST plug-in, which provides a realistic piano timbre. We were careful to make the counterparts sound as though they were performed on an acoustic piano. Variations of tempo in Kempf and Södergren's recordings were extracted and transferred onto the MIDI files of the counterparts. The musical material was played under the control of a Macintosh ibook G3 over Sennheiser HD 200 headphones at a comfortable loudness level. We used an interface programmed with Macromedia Director MX 2004 Software. The sound qualities of the counterparts were evaluated as extremely good by three musical experts, and were confirmed by all participants. ${ }^{1}$

\section{Procedure}

Participants were informed that they would listen to four piano pieces three times each. Presentation order of the pieces was randomly selected across participants. The experimental procedure was split into three tasks. In Task 1, participants were asked to listen to each piece once. They had to indicate the onset of each new musical idea with a click of a mouse on the appropriate icon.

\footnotetext{
${ }^{1}$ The stimuli can be listened to at http://leadserv.u-bourgogne.fr/ lalitte/exemplesWEST.html
} 

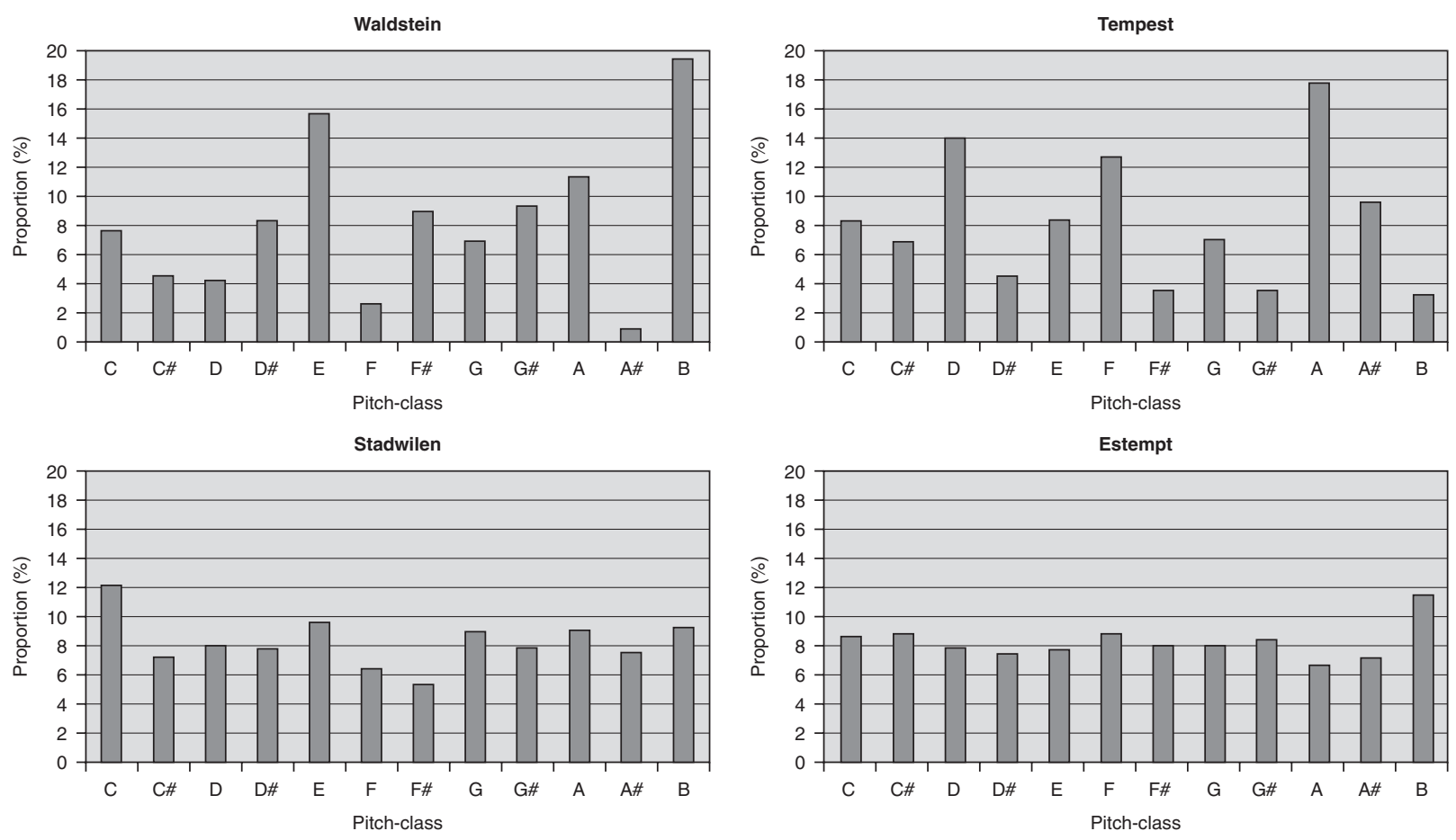

FIGURE 1. Frequency of occurrence of pitch classes in Beethoven's sonatas and atonal variant counterparts.

Participants were not given any information about the duration of musical ideas or about the number of ideas in the excerpt. The label of the piece (Piece 1, Piece 2, etc.) was shown on the screen above the horizontal line representing the flow of music in time, with all the new musical ideas already identified marked with a red dash. Having completed this task for the four pieces, participants passed to the second task.

In Task 2, participants were asked to indicate how stimulating or relaxing the music was at each point of time by moving a mouse pointer on a continuous response computer interface. Participants moved the pointer up when music was stimulating, and moved it down when it was relaxing. Participants were asked to use the maximum range of the line representing the bipolar dimension of stimulation/relaxation. Having performed this task for all four pieces, participants performed the third task.

In Task 3, participants were asked again to indicate the onset of each new musical idea, but now they were allowed to move along the piece with a horizontal slider, from one moment to another, to stop, to listen again, and to remove or to replace markers. As online segmentation and continuous judgment of musical arousal were performed prior to this task, in the retrospective segmentation task, participants were assumed to already be familiar with the structure of the experimental material. After performing the retrospective task for the four pieces, participants were asked to estimate the similarity of all the pairs of pieces and their familiarity with each piece. Response options available for the similarity estimate were "very similar" and "little similar," and those available for the familiarity estimate were "very familiar" and "little familiar." When the participants finished this task, they were debriefed.

\section{Results}

Participants with music training reported higher familiarity with the excepts, whether they were tonal, $t(50)=$ $5.20, p<.001$, or atonal, $t(50)=3.03, p<.005$. Listeners generally perceived tonal pieces as more familiar than atonal ones, $t(51)=4.11, p<.002$. Similarity judgments were mostly influenced by the pitch content (tonal versus atonal) of the pieces. Most of the musicians (75\%) found Waldstein similar to Tempest, whereas only 25\% found Waldstein similar to Stadtwilen, and $17 \%$ found Tempest similar to Estempt. By contrast, most of them (81\%) found the two atonal pieces similar. Nonmusicians usually responded that these pieces were dissimilar, but the percentage of "dissimilar" responses weakly varied among conditions (ranking from $60 \%$ to $50 \%$ for the 

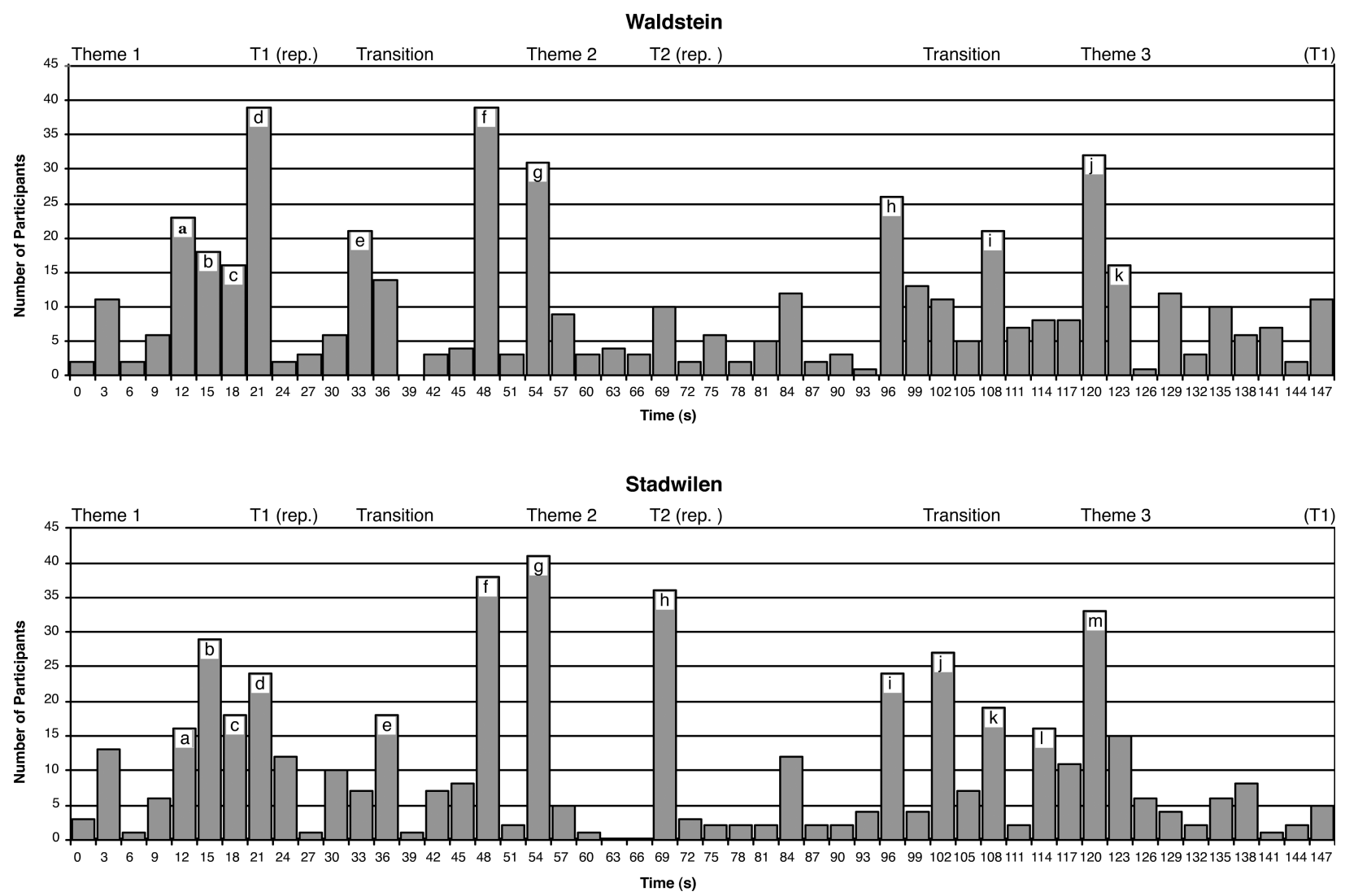

FIGURE 2. Perceived musical ideas by nonmusicians and musicians in real-time segmentation task: Waldstein sonata (upper panel) and its atonal variant Stadwilen (lower panel). Major segments whose boundaries were agreed on by at least $33 \%$ of all participants are indicated by letters ( $a$, $b$, c, etc.) into the bars. Main theoretic subsections are indicated above the panels.

highest and lowest values). At the debriefing stage, it turned out that both groups were unaware of the temporal similarity within the original-counterpart pairs (Waldstein/Stadwilen, Tempest/Estempt). So, pitch content had a strong effect on the similarity judgments.

Given the strong influence of tonal structure on perceived similarities, it was of interest to assess whether removing pitch stability did reorganize the musical ideas of the pieces. In analyzing the temporal location of the perceived ideas we took account of a lag between musical events and responses to them, which were therefore aggregated and averaged for each $3 \mathrm{~s}$ of the musical flow. The results of segmentation are displayed in Figures 2 and 3. The major segments (whose boundaries were agreed on by at least $33 \%$ of all the participants) are represented by letters ( $a, b, c$, etc.) into the bars. Figure 2 shows that in Waldstein participants distinguished 11 major segments, which corresponded mostly to large changes in the thematic organization. Musicians and nonmusicians showed strong agreement in indicating the onset of a new musical idea on the appearance of the second presentation of Theme 1 (69\% and $75 \%$ respectively, at 21-24 s), the first presentation of Theme 2 (39\% and 94\% respectively, at 54-57 s), and the first presentation of Theme 3 (50\% and 75\% respectively, at 120-123 s). Both groups consistently perceived a change at the beginning of the short transitional passage leading to Theme $2(75 \%$ and $69 \%$, at 48-51 s). A few segments did not fit with a significant change in rhetorical structure $(61 \%$ at $96-99 \mathrm{~s}$ in nonmusicians; $44 \%$ at $102-105 \mathrm{~s}$ in musicians). Participants perceived 13 major changes in Stadwilen.

As shown in Figure 3, 11 major musical ideas were indicated by participants in Tempest. The three extreme changes in movement (Allegro, Largo, Allegro) at the beginning of the piece (15-18 s, 30-33 s, 42-45 s) were strongly perceived. Musicians and nonmusicians (39\% and 59\% respectively, at 57-60 s) considered the presentation of the main theme as a new musical idea. No group systematically responded to the reprise of the exposition (147-150 s). In Estempt, 12 major changes were perceived by participants. Almost all major segments in 


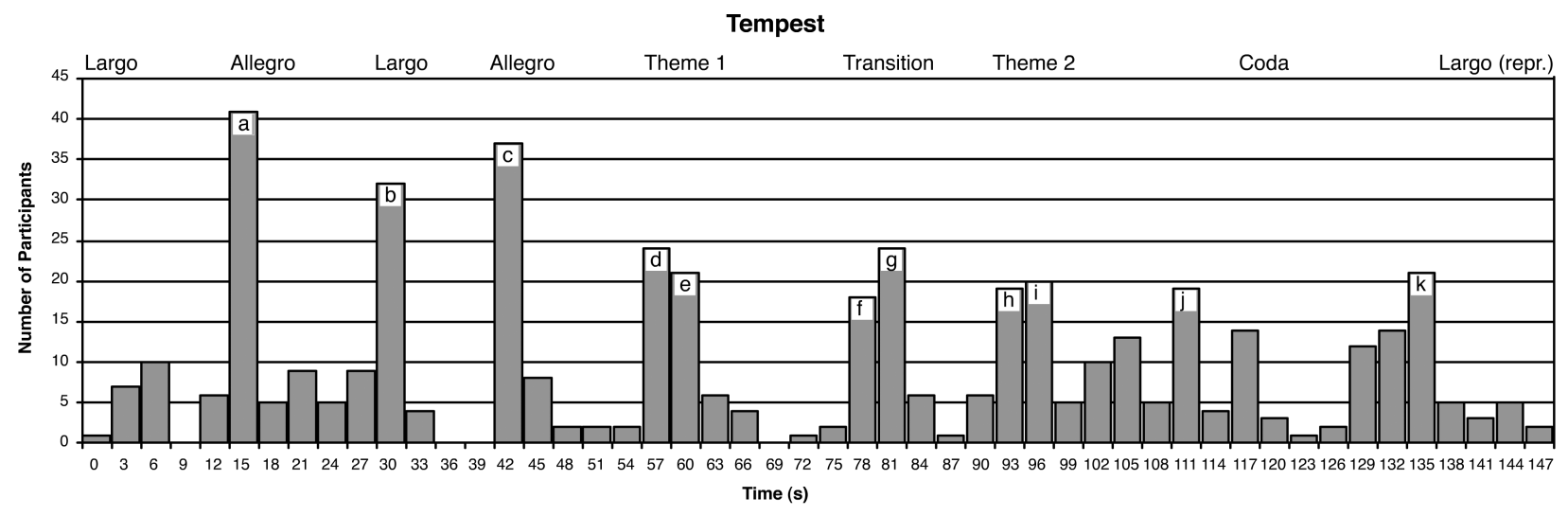

Estempt

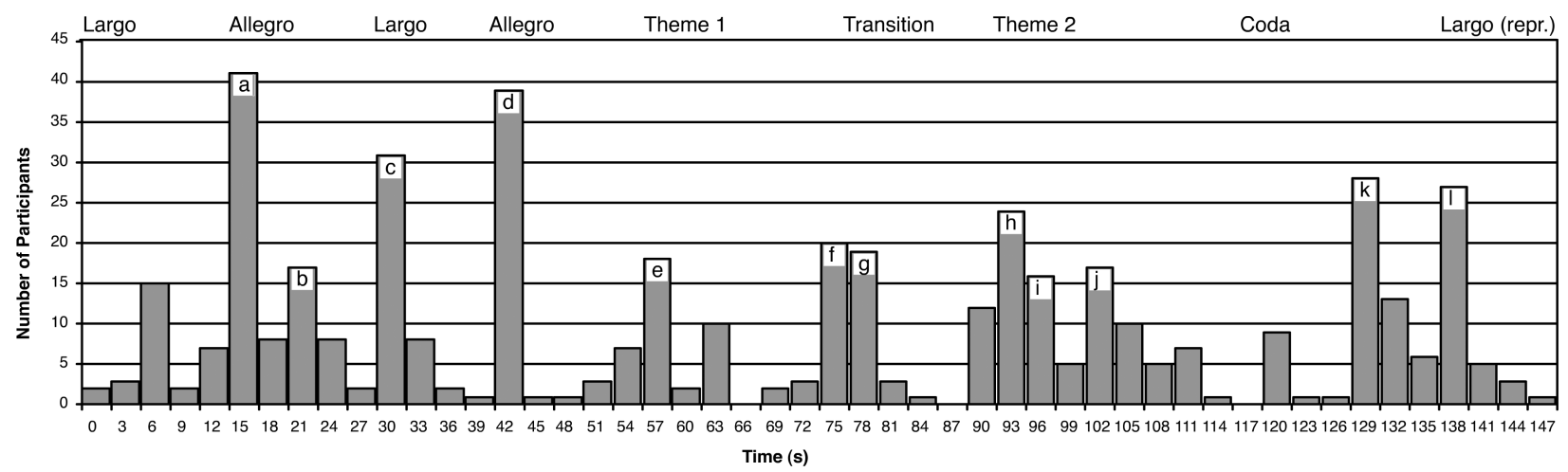

FIGURE 3. Perceived musical ideas by nonmusicians and musicians in real-time segmentation task: Tempest sonata (upper panel) and its atonal variant Estempt (lower panel). Major segments whose boundaries were agreed on by at least $33 \%$ of all participants are indicated by letters (a, b, $c$, etc.) into the bars. Main theoretic subsections are indicated above the panels. Main theoretic subsections are indicated above the panels.

the counterpart pieces (Stadwilen/Estempt) were located exactly as in the original pieces (Waldstein/Tempest); however, the consistency of response was slightly less.

High correlations were found between segmentation of original and variant counterpart pieces (Waldstein/ Stadwilen, Tempest/Estempt; Table 1). No correlation was found either between the two original (Waldstein/ Tempest), or two counterpart pieces (Stadwilen/ Estempt). Even though participants were unaware of the similarity between the original pieces and their atonal counterparts, the perceived musical ideas were located at the same place in the originals and counterparts.

There were highly significant correlations between segmentations performed in the real-time and retrospective tasks (Table 2), indicating that the originals and their counterparts were segmented similarly. No correlations were found either between the two originals (Waldstein/ Tempest) or the two counterparts (Stadwilen/Estempt). In addition, significant correlations were found

TABLE 1. Correlation Coefficients for the Segmentation of Originals and Counterparts by Musicians and Nonmusicians in Real-Time and Retrospective Tasks.

\begin{tabular}{llllrrrr}
\hline & Pair & W/S & T/E & W/T & S/E & W/E & T/S \\
\hline Real-time Task & Nonmusicians & $.67 *$ & $.64 *$ & .03 & .07 & -.04 & .04 \\
& Musicians & $.74 *$ & $.71 *$ & -.22 & .10 & -.04 & -.04 \\
Retrospective Task & Nonmusicians & $.74 *$ & $.62 *$ & .01 & .11 & .19 & -.05 \\
& Musicians & $.88 *$ & $.82 *$ & -.01 & .14 & .17 & .03 \\
\hline
\end{tabular}

$* p<.0001$ 
TABLE 2. Correlation Coefficients for the Segmentation of Four Musical Pieces in the Real-Time and Retrospective Tasks.

\begin{tabular}{lcccc}
\hline Pieces & Waldstein & Stadwilen & Tempest & Estempt \\
\hline Nonmusicians & $.87 * *$ & $.87 * *$ & $.80 * *$ & $.88 * *$ \\
Musicians & $.74 * *$ & $.48 *$ & $.78 * *$ & $.75 * *$ \\
\hline
\end{tabular}

$* p<.001, * * p<.0001$

between musicians' and nonmusicians' for both realtime and retrospective segmentation (Table 3 ). This suggests that musical expertise only weakly affects the perceived location of musical ideas.

The pattern of estimated musical arousal over time is displayed in Figure 4, averaged over both groups. Responses were found to reflect the musical structure of both the tonal and the atonal pieces. The contours of the arousal curve for two original/counterpart pairs were highly correlated, Waldstein/Stadwilen, $r(146)=.77, p<$ .001 , Tempest/Estempt, $r(146)=.93, \mathrm{p}<.001$. Based on strength of arousal, Waldstein and Stadwilen can be divided into three main zones corresponding to three major thematic groups. The highly arousing introductory zone was followed by a zone with low and gradually increasing arousal. The third zone was high in arousal and finished with gradual relaxation. These main changes in arousal reflect the expressive pattern-high energy, low energy, gradual increasing/decreasing energy - of the exposition of the piece. In Waldstein, the location of the onset of perceived musical ideas in most cases corresponded to the changes in direction of the arousal curve, whereas in Stadwilen the relationship between the location of perceived musical ideas and arousal was less systematic. Variations in the arousing properties of Tempest and Estempt were strongly related to two parts of the introduction (repeated Largo and Allegro), and further, to the main theme. A short, relaxing segment marks the end of the exposition. In the introductions of Tempest and Estempt, the location of the onsets of musical ideas precisely matched the transitions between Largo and Allegro, indicated also by rapid changes in the estimated arousal. In Tempest, the two following musical ideas (theme 1 and transition) were marked by rapid relaxation.
The beginning of the next segment was associated with Theme 2, introducing chords in the low register. In Estempt, Theme 1 was marked by a high arousal plateau and Theme 2 was matched with the changes in direction of the arousal curve.

A GLM repeated measures ANOVA was performed on arousal responses, with tonality/atonality as a withinsubject factor and musical expertise as a between-subject factor. There was a main effect of listeners' musical expertise, $F(1,47)=7.67, p<.01(M S E=17.48)$, a main effect of musical tonality, $F(1,47)=9.39, p<.005$ (MSE $=$ $7.05)$, and a significant two way interaction, $F(1,47)=$ $8.85, p=.005(M S E=6.63)$. Musicians perceived tonal music as less stimulating than atonal music (3.95 versus $4.75, p<.005)$, whereas nonmusicians considered them as equally arousing ( 4.98 versus 4.99 ). Tonal pieces were judged as more relaxing by musicians than non-musicians for Waldstein, $F(1,34)=23.68, p=.005$ and Tempest, $F(1,34)=5.03, p<.05)$. In atonal pieces the relations were less systematic and less salient. The arousal of Stadwilen and Estempt as estimated by musicians and nonmusicians did not differ significantly.

The last analysis investigated the possible contribution of psychoacoustic features to arousal responses. Time-series analytic techniques were applied. To explain the variance in musical arousal we used a multiple regression model comprising an autoregression term and six musical variables. The autoregressive coefficient indicates the correlation of each point in the time-series data with the most recent response (that is, "lag 1" or "first order autocorrelation," Schubert, 2004a). The basic psychoacoustic features of music chosen for analysis were the level of dBA (loudness), zero-crossing rate (ZCR), spectral centroid, roughness,

TABLE 3. Correlation Coefficients of Musicians' and Nonmusicians' Segmentation of Four Musical Excerpts in Real-Time and Retrospective Tasks.

\begin{tabular}{lcccc}
\hline & Waldstein & Stadwilen & Tempest & Estempt \\
\hline Real-time Task & $.74 *$ & $.81 *$ & $.80 *$ & $.93 *$ \\
Retrospective Task & $.69 *$ & $.77 *$ & $.81 *$ & $.82 *$ \\
\hline
\end{tabular}

$* p<.0001$ 

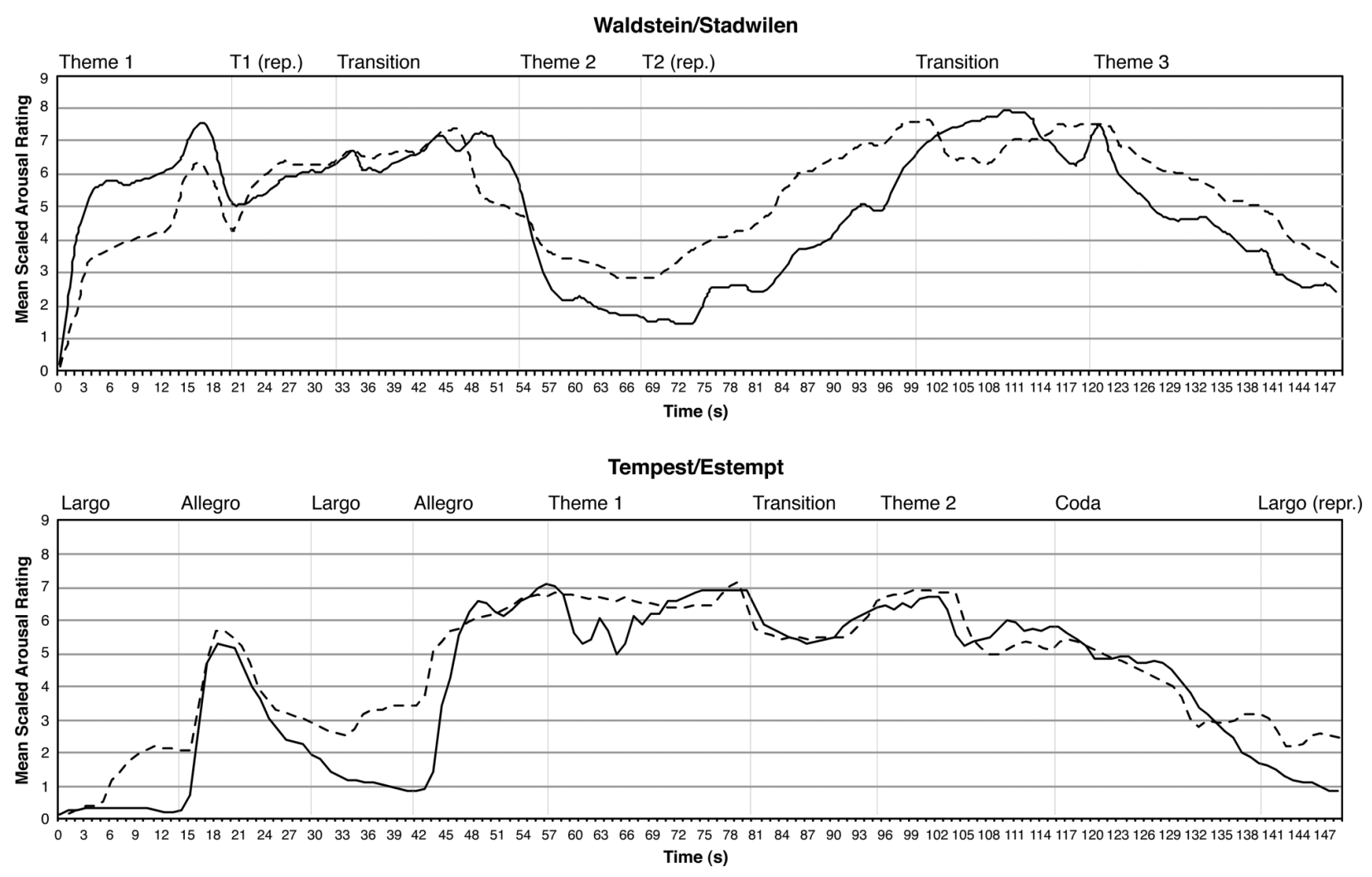

FIGURE 4. Estimated musical arousal averaged over nonmusicians and musicians: upper panel = Waldstein sonata (solid line) and its atonal variant Stadwilen (dotted line), lower panel = Tempest sonata (solid line) and its atonal variant Estempt (dotted line). Main theoretical subsections are indicated above the panels.

pitch periodicity flux (PP flux), and spectral roll-off. These features were computed from the output of an auditory model by Leman, Lesaffre, \& Tanghe (2001). To test psychoacoustic aspects of music that may explain variance in musical arousal, we followed the example of Schubert's time-series analysis (2004b), considering a lag between the onset of musical events and listeners' responses. All variables were differenced to produce a gradient time series, indicating the second-to-second change in each of the variables (Schubert, 2004b).

Principal component analysis of the psychoacoustic variables revealed two main psychoacoustic factors, AX1 and AX2, which were entered in the model together with tempo and the autoregressive term. AX1 combines loudness, centroid, roughness, and roll-off, and AX2 combines PP flux and ZCR. Z-values for all the variables were entered in the regression model, which explains a comparable share of variation in the arousing properties of the music as perceived by musicians and nonmusicians. Since both groups show a congruent pattern of changes over time in the determining power of the individual psychoacoustic parameters, we report the overall data with no regard for musical expertise. As shown in Table 4, the variance in the arousal value of all the pieces considered is best explained by the model with lags 0 and 1 . The proposed model of changes in the estimated arousal of music explains $38-50 \%$ of variability in the arousal judgments. The autoregressive term is the most powerful element of the model, explaining $56-71 \%$ of variance in the dependent variable. The estimated musical arousal is a product of the interaction of arousing potential of the preceding musical events, current psychoacoustic features (grouped in the two principal components), and tempo. The most powerful and stable object-related determinant of musical arousal is AX1 (comprising loudness, centroid, roughness, and roll-off-features of sound related to intensity and timbre). Contribution to the model was consistent but rather modest compared to the autoregressive term. Only in Waldstein, where small variations of tempo occurred, did this variable significantly predict the arousal properties of the music at lag 1. The time lag used in the correlation between 
TABLE 4. First-Order Autoregression Models of the Perceived Stimulatory Value of Music.

\begin{tabular}{|c|c|c|c|c|c|}
\hline & lag 0 & $\operatorname{lag} 1$ & lag 2 & lag 3 & $\operatorname{lag} 4$ \\
\hline \multicolumn{6}{|c|}{ Waldstein } \\
\hline$R^{2}$ & $.52 * *$ & $.59 * *$ & $.50 * *$ & $.51 * *$ & $.51 * *$ \\
\hline AR1 & $.71 * *$ & $.66 * *$ & $.70 * *$ & $.68 * *$ & $.69 * *$ \\
\hline AX1 & $.20 * *$ & $.32 * *$ & -.00 & -.00 & -.10 \\
\hline AX2 & -.01 & -.10 & .11 & .01 & .09 \\
\hline Tempo & -.05 & -.07 & .12 & $.18 *$ & .12 \\
\hline \multicolumn{6}{|c|}{ Stadwilen } \\
\hline$R^{2}$ & $.49 * *$ & $.47 * *$ & $.44 * *$ & $.46 * *$ & $.45 * *$ \\
\hline AR1 & $.64 * *$ & $.64 * *$ & $.68 * *$ & $.67 * *$ & $.67 * *$ \\
\hline AX1 & $.20 * *$ & .03 & -.04 & -.13 & -.05 \\
\hline AX2 & -.12 & $-.17 *$ & .05 & -.09 & .11 \\
\hline Tempo & -.04 & .05 & .01 & .03 & .06 \\
\hline \multicolumn{6}{|c|}{ Tempest } \\
\hline$R^{2}$ & $.48 * *$ & $.46 * *$ & $.39 * *$ & $.41 * *$ & $.38 * *$ \\
\hline AR1 & $.59 * *$ & $.56 * *$ & $.63 * *$ & $.62 * *$ & $.62 * *$ \\
\hline AX1 & $-.27 * *$ & $-.27 * *$ & .02 & .11 & .00 \\
\hline AX2 & -.03 & .11 & .10 & .09 & .03 \\
\hline Tempo & .15 & -.06 & .01 & .03 & -.03 \\
\hline \multicolumn{6}{|c|}{ Estempt } \\
\hline$R^{2}$ & $.44 * *$ & $.45 * *$ & $.41 * *$ & $.41 * *$ & $.40 * *$ \\
\hline AR1 & $.62 * *$ & $.58 * *$ & $.61 * *$ & $.66 * *$ & $.64 * *$ \\
\hline AX1 & $-.18 *$ & $-.21 *$ & -.05 & .09 & .06 \\
\hline AX2 & .05 & .06 & .06 & -.00 & -.02 \\
\hline Tempo & -.06 & .08 & .04 & .03 & -.03 \\
\hline \multicolumn{6}{|c|}{ All pieces } \\
\hline $\mathrm{R}^{2}$ & $.44 * *$ & $.45 * *$ & $.43 * *$ & $.43 * *$ & $.43 * *$ \\
\hline AR1 & $.65 * *$ & $.64 * *$ & $.64 * *$ & $.65 * *$ & $.65 * *$ \\
\hline AX1 & $-.09 * *$ & $-.14 * *$ & -.02 & .00 & -.00 \\
\hline AX2 & .04 & $.10 * *$ & .05 & .02 & .00 \\
\hline tempo & .03 & -.00 & .05 & .06 & .04 \\
\hline
\end{tabular}

Note. As in Schubert (2004b) standard coefficients (beta) are shown to allow comparison across variables. They indicate a relative contribution of each psychoacoustic variable to the perceived stimulatory value of music. $R^{2}=$ approximate model fit, $\mathrm{AR} 1=$ coefficient for first order autoregression term, $\mathrm{AX} 1=$ psychoacoustic factor combining loudness, centroid, roughness, and roll-off, AX2 = psychoacoustic factor combining PP flux and ZCR, Tempo = coefficient for change in tempo (units of variable: beats per minute). $* p<.01, * * p<.001$

changes in tempo and estimated musical arousal was necessary to synthesize temporal information, whereas the response to changes in AX1 was instantaneous or delayed by lag 1 at most. In all pieces, AX1 was a stronger contributor to the arousal properties of the music than tempo, which corresponds very well with the results on arousal obtained by Schubert (2004b) for tonal excerpts. In Estempt, the explanatory powers of AX1 and tempo were balanced. In both atonal pieces, the AX2 factor explained a significant share of variation in participants' estimates of music's arousal power. The modest contribution of the psychoacoustic variables to the model suggests that the sensory level of music perception is a basic but limited determinant of musical arousal.

\section{General Discussion}

The main purpose of the present study was to investigate the influence of tonal relationships on the perception of large-scale structure of four musical pieces. Because the pitch content was drastically changed, participants did not perceive the similarity of the original pieces to their counterparts. Most of the participants with music training found the two tonal sonatas more similar (despite their considerable difference) than the originals and counterparts that shared the same rhythm, loudness changes, phrasing, and rhetorical structure. However, in spite of the fact that pitch stabilities of the pieces were deeply altered, the location of 
perceived musical ideas and the contours of stimulation/relaxation curves were very much alike. This suggests that participants were able to feel, implicitly, some invariance between originals and counterparts.

What type of invariant structure could be perceived when the pitch structure of a piece had been drastically altered? The outcome of the psychoacoustic analysis suggests that such invariance in unlikely to occur at a sensory level. The psychoacoustic qualities of the original and counterpart pieces were not related enough to account for arousal measures. Participants were probably sensitive to the similarity of the rhythm, but given the length of the excerpt, it seems unlikely that this similarity was enough to account for the similarity in the segmentation task and arousal measures. We therefore are led to consider that participants' responses were governed in both tasks by a more abstract dimension of music. One global structure that was kept unchanged in this study was that defined by the relationships between the different motifs of the pieces. That is to say, the rhetorical aspects of the original pieces were preserved in the atonal counterparts. Musical rhetoric can be viewed as the way in which composers organize their own musical discourse: the type of musical ideas (theme, bridge, transition, development, conclusion) and the way they are sequenced (continuous, contrasted). Musical rhetoric is comparable to linguistic rhetoric in the sense that rhetoric relates to logic and intent. Such rhetorical organization defines a larger level of time in music than in language. It seems likely that participant's responses were influenced in the segmentation task and arousal measure by the similarity of the rhetorical structures of the originals and counterparts.

In origin, rhetoric was considered the art of speech and persuasion. One of the parts of the ancient guide to rhetoric, the Dispositio, concerned the plan-the sequence of ideas - that organized a discourse. During the Baroque era, there was a large amount of research on the potential equivalence between rules of rhetoric and musical discourse (Heinichen, 1728; Kircher, 1650; Mattheson, 1954). Today, after a period strongly marked by structuralism, some concepts of rhetoric have reappeared in various forms (Berry, 1989; Caplin, 1998; Cooke, 1959; Hatten, 2004; Ratner, 1980). Ratner's Classical Music (1980) referred explicitly to rhetorical concepts (exordium, circumlocution, gradatio, peroration, etc). Caplin (1998) has analyzed works of the Classical period in terms of formal functions. His theory clearly distinguishes formal function from grouping structure (topic, transition, exposure, coda, previous, consequent, etc). According to Hatten (2004) the three basic formal functions in the Classical style (thematic/presentational, transitional/developmental and cadential/closural) are defined in terms of several different polar variables such as periodicity/aperiodicity of phrase structures, stability/instability of tonal materials, conventionality/unconventionality of musical ideas. Thus, musical significance is due not only to the structural relations in the material, but also to the formal functions constituting a succession of musical events. In this way, large-scale structure no longer is viewed only as a tonal scheme or architecture, but as a set of functions and strategies, such as repetition, contrast, amplification, progression, contradiction, conclusion, and so on. Our finding provides some support for this concept of musical rhetoric. Such a level of musical organization exists even in the absence of tonal hierarchies. Our data even suggest that this level remains invariant when the tonal structure of a given piece is entirely removed. Our atonal counterparts thus may be viewed as musical variations that do not deeply alter the forms of the tonal pieces from which they were derived.

Finally, the present finding sheds new light on the psychological reality of large-scale structures in music. A striking finding is the strong discrepancy between the explicit judgments of similarity and those of segmentation and arousal. When asked to judge explicitly the similarity of pairs of musical excerpts, musicians based their judgments on musical style (classical vs. contemporary) and harmonic features (tonal vs. atonal). As a consequence they considered the original and counterparts very different (no one reported having perceived the link between these pieces), and more dissimilar than the two original Beethoven sonatas. By contrast, the segmentation task and the arousal judgment revealed that participants actually perceived the similar organization of original and counterpart. This finding suggests that participants may be sensitive to large-scale structures in music (both tonal and atonal) even though they are not able to detect explicitly when this structure was manipulated (see McAdams et al., 2004, and Lalitte \& Bigand, 2006, for convergent findings). Interestingly, music training was not found to modulate the listeners' sensitivity to large-scale structures, which is consistent with data reported by Bigand and Poulin-Charronnat (2006). Most of the research on the perceptual reality of largescale structure in music (defined by tonal or motivic relationships) uses explicit tasks. With such tasks, participants are found to be weakly sensitive to this level of organization. Implicit tasks tap into musical abilities that are not accessible with explicit tasks (Tillmann, Bharucha, \& Bigand, 2000). Using such implicit tasks 
may lead to our reconsidering the psychological reality of large-scale structures in music.

\section{Author Note}

This research was supported by the Conseil Régional de Bourgogne/EGIDE and the grant for the French National Agency for Research (ANR) "Mémoire: la musique est-elle spéciale?" We would like to thank
Stéphane Argon for developing the software used for the experiment and Paul Molin for his advice on statistics.

Correspondence concerning this article should be addressed to Philippe Lalitte, LEAD-CNRS Université de Bourgogne, Pôle AAFE Esplanade Erasme, BP 26513 21065 Dijon cedex France. E-MAIL: Philippe.Lalitte@ u-bourgogne.fr

\section{References}

BERRY, W. (1989). Musical structure and performance. New Haven, CT: Yale University Press.

Bigand, E. (2003). More about the musical expertise of musically untrained listeners. Annals of the New York Academy of Sciences, 999, 1-10.

Bigand, E., \& Poulin-Charronnat, B. (2006). Are we "experienced listeners"? A review of the musical capacities that do not depend on formal musical training. Cognition, 100, 100-130.

Caplin, W. E. (1998). Classical form. Oxford: Oxford University Press.

Clarke, F. (1987). Levels of structure in the organization of musical time. Contemporary Music Review, 2, 211-237.

Clarke, E., \& Krumhansl, C. (1990). Perceiving musical time. Music Perception, 7, 213-251.

Cook, N. (1987). The perception of large-scale tonal closure. Music Perception, 5, 197-205.

Cooke, D. (1959). The language of music. London: Oxford University Press.

Cooper, G. W., \& Meyer, L. B. (1960). The rhythmic structure of music. Chicago: University of Chicago Press.

Czerny, C. (1979). School of practical composition: Complete treatise on the composition of all kinds of music (J. Beshop, Trans.). New York: Da Capo Press. (Reprinted from Die schule der praktischen tonsetzkunst, 1849, Bonn: Simrock)

Deliège, I. (1989). A perceptual approach to contemporary musical forms. Contemporary Music Review, 4, 213-230.

FrAnCÈs, R. (1958). La perception de la musique [The perception of music]. Paris: Librairie Philosophique J. Vrin.

Gottlieb, H., \& Konecni, V. (1985). The effect of instrumentation, playing style, and structure in the Goldberg Variations by Johann Sebastian Bach. Music Perception, 3, 87-102.

Hatten, R. S. (2004). Musical meaning in Beethoven. Markedness, correlation, and interpretation. Bloomington and Indianapolis: Indiana University Press.

Heinichen, J. D. (1728). Der Generalbass in der Composition [Basso continuo in composition]. Dresden. Facs. Hildesheim, Olms, 1969.
Karno, M., \& Konecni, V. (1992). The effect of structural interventions in the first movement of Mozart' Symphony in $G$ Minor K. 550 on aesthetic preference. Music Perception, 10, 63-72.

Kinberger, J. P. (1757). Der allezeitfertige polonaisen und menuettencomponist [The universal polonaise and menuet composer]. Berlin: G. Ludewig Winter.

KIRCHER, A. (1650). Musurgia universalis [Universal work of the muses]. Rome: Corbelletti.

КосH, H. C. (1983). Introductory essay on composition (N. K. Baker, Trans.). New Haven, CT: Yale University Press. (Reprinted from Versuch einer anleitung zur composition, 1782-1793, Leipzig: A.F. Böhme)

Lalitte, P., \& Bigand, E. (2006). Music in the moment: Revisiting the effect of large-scale structure. Perceptual and Motor Skills, 103, 811-828.

Lalitte, P., Bigand, E., Poulin-Charronat, B., McAdams, S., Delbé, C., \& D’Adamo, D. (2004). The perceptual structure of thematic materials in The Angel of Death. Music Perception, 22, 265-296.

Leman, M., Lesaffre, M., \& TANGhe, K. (2001). Introduction to the IPEM toolbox for perception-based music analysis. The Online Contemporary Music Journal, 7. Retrieved September 28, 2008, from http://www.mikropol.net

LeRDAHL, F. (2001). Tonal pitch space. New York: Oxford University Press.

LERDAHL F., \& JACKENDOFF R. (1983). A generative theory of tonal music, Cambrige, MA: MIT Press.

Marvin, E. W., \& Brinkman, A. (1999). The effect of modulation and formal manipulation on perception of tonic closure by expert listeners. Music Perception, 16, 389-407.

MarX A. B. (1841-1847). Die Lehre von der musikalischen Komposition, praktisch-theoretisch [The science of musical composition. Practice and theory: Vol. 1-4]. Leipzig: Breitkopf und Härtel.

Mattheson, J. (1954). Dokumenta musicological (I. Reihe, Trans., M. Riemann, Ed.). Kassel: Bärenreiter-Verlag. (Reprinted from Der Volkommene Capellmeister [The complete music director], 1739, Hamburg: Herold). 
McAdams, S., Vines, B. W., Vieillard, S., Smith, B. K., \& REYNOLDS, R. (2004). Influences of large-scale form on continuous ratings in response to a contemporary piece in a live concert setting. Music Perception, 22, 297-350.

De Momigny, J. J. (1806). Cours complet d'harmonie et de composition, d'après une théorie neuve et générale de la musique [Complete course of harmony and composition, from a new and general theory of music]. Paris: Momigny and Bailleul.

Ratner, L. (1980). Classic music: Expression, form and style. New York: Schirmer Books.

Riemann, H. (1882). Musik lexicon. Leipzig: Verlag des Bibliographishen Instituts.

SAlzer, F. (1952). Structural hearing: Tonal coherence in music. New York: Dover Publications.

Schenker, H. (1979). Free composition (E. Oster, Trans.). New York: Longman. (Original work published 1935).

SCHERING, A. (1911). Musikalische Bildung und Erziehung zum musikalischen Hören [Musical education and musical hearing]. Leipzig: Quelle und Meyer.
SChubert, E. (2004a, April). Research in expressing continuous emotional response to music as a function of its psychoacoustic parameters: Current and future directions. Paper presented at the meeting of the 18th International Congress on Acoustics, Kyoto, Japan.

SCHUBERT, E. (2004b). Modeling perceived emotion with continuous musical features. Music Perception, 21, 561-585.

Tillmann, B., Bharucha, J. J., \& Bigand, E. (2000). Implicit learning of tonality: A self-organizing approach. Psychology Review, 107, 885-913.

Tillmann, B., \& Bigand, E. (1996). Does formal musical structure affect perception of musical expressiveness? Psychology of Music, 24, 3-17.

Tillmann, B., Bigand, E., \& Madurell, F. (1998). Local versus global processing of harmonic cadences in the solution of musical puzzles. Psychological Research, 61, 157-174.

Zвікоwski, L. M. (2002). Conceptualizing music. Oxford: Oxford University Press. 